\title{
Needle and Syringe Exchange Program for HIV/AIDS Prevention : Areas to be Considered by Law Enforcement Agency for Implementation
}

\author{
Ezarina Zakaria, Fauziah Ibrahim, Norulhuda Sarnon, Nazirah Hassan
}

\begin{abstract}
Needle and Syringe Exchange Programme (NSEP) is a HIV/AIDS prevention programme targeting hardcore drug addicts. NSEP encourages addicts to exchange used needles with new syringe for free. The NSEP in Malaysia involves the cooperation of multi-sector agencies such as the Ministry of Health (MOH), the Royal Malaysian Police (RMP) and the Malaysian AIDS Council (MAC). The implementation of the NSEP creates controversy when it being seen to encourage continuous drug addicts activities and solely focus on HIV/AIDS prevention. An exploratory study being conducted to examine the involvement of multisectoral in the NSEP. This article would only discuss RMP's findings with regards to its discretionary dilemma as a drug law enforcement agency. Five police officers of the Narcotics Crime Investigation Department were selected as informants. Data collection being carried out by using an in-depth interview method. The analyses form theme from data that being carried out inductively. This article would discuss only two of the overall studies: $i$ ) the form of discretion given by the RMP to NSEP clients and ii) the challenges encountered by RMP in defending its discretion. The findings highlighted dilemma encountered by police on their discretion not to arrest or impose any detention procedures towards NSEP clients. The RMP found it difficult to exercise discretion towards client because: $i)$ the discretion not to arrest the addict was against the law, ii) the RMP was concerned about the misuse of discretion by the client and iii) the discretionary giving could affect public perception of RMP responsibility and integrity. The study proposes a module in implementing the NSEP on a multisectoral network especially involving the police.
\end{abstract}

Keywords: police discretion, NSEP, HIV/AIDS, law enforcement

\section{INTRODUCTION}

The Needle and Syringe Exchange Programme (NSEP) is an HIV/AIDS prevention programme that uses harm reduction approaches. NSEP is a remedial intervention aimed at reducing the prevalence of HIV/AIDS among hardcore drug users sharing syringes. NSEP encourages addicts to come forward to exchange used needle with clean syringe for free.

Revised Manuscript Received on September 25, 2019

Ezarina Zakaria, School of Psychology and Human Development, Faculty of Social Science and Humanities, National University of Malaysia, 43600 Bangi, Selangor, MALAYSIA.

Fauziah Ibrahim, School of Psychology and Human Development, Faculty of Social Science and Humanities, National University of Malaysia, 43600 Bangi, Selangor, MALAYSIA.

Norulhuda Sarnon, School of Psychology and Human Development, Faculty of Social Science and Humanities, National University of Malaysia, 43600 Bangi, Selangor, MALAYSIA.
The World Health Organization (WHO) has outlined the NSEP as a more practical intervention to combat the spread of HIV not only among addicts but also indirectly to the general public [1-2]. The reduction of harm interventions such as the NSEP have begun to gain extensive acceptance in Asia Pacific especially Bangladesh, China, India, Indonesia, Malaysia, Myanmar, Pakistan and Vietnam. These countries reported the expand of the services even though access to it do not fully meet client's demands [3]. In fact, some of the 37 countries in the Asia-Pacific region that provide harm reduction services in particular the NSEP, still impose prisons as a means of punishment for drug addicts.

The NSEP was first implemented in Malaysia as a pilot project in 2006 and received full support from the government, although according to Baba [4] it received mix reaction from the public in its early stages when it was first proposed. The NSEP is not an effort that is being easily accepted by the public and it creates controversial in many countries that implementing it because it is being evaluated as encouraging addicts, as well as contrary to the zero tolerance recovery and the law on drugs [5-8].

Malaysia has been combating drug abuse for a period of time and become more prominent since 1997 and aimed to be drug free country in 2015. Although Malaysia is widely recognised as a country with strict enforcement on drugs, the drug abuse and transmission of HIV/AIDS remains an unresolved challenge [3]. Until today, the Dangerous Drugs (Special Preventive Measures) Act 1985 has not being able to prevent drug abuse among Intravenous Drug Users (IDU) in Malaysia [9]. The prevalence of HIV/AIDS among IDUs also remains the same. To date, there is no state in Malaysia that is free of HIV/AIDS or drugs. Statistics of HIV cases in the country as at the end of 2014 have increased cumulatively to 105,189 cases. In 1997, heroin was the most popular drug among the IDU in Malaysia, followed by morphine and cannabis. Meanwhile, injection is the preferred method among IDU to take heroin. IDUs in Malaysia share syringes and injection equipment too. Although Malaysia implemented harm reduction through the NSEP intervention, the Dangerous Drugs (Special Preventive Measures) Act 1985 still technically prohibits the possession of syringes and needles without medical prescription. 


\section{LITERATURE REVIEW}

\section{A. PROHIBITIONIST POLICY vs HARM REDUCTION}

The prohibitionist ideology has dominated how Malaysia focuses on the treatment, recovery and enforcement of drug laws in the country. Whereas, harm reduction movement at the international level would focused more on principles, objectives and methods that go against the prohibitionist drug policy [8-13]. The prohibitionist group strongly holds the philosophy that drug abuse could only be dealt with by means of punishment and legal enforcement. Harm reduction is in contrast to prohibitionist ideology-based remedies as it focuses more on shifting drug rehabilitation from punishment to a more open and concerning human rights of the IDUs [14]. In fact, proponents of the harm reduction movement feels that the enforcement actually worsen the risk caused by drugs [10].

This prohibitionist policy is in line with the model of moral or criminal justice as it was belief that drug abuse is morally wrong and should be classified as a form of crime that threatens national security [10]. Prohibitionists evaluate IDUs as devians who should be punished to prevent them from continuing to abuse drugs. Furthermore, sanctions have also become the instrument in planning drug rehabilitation programmes in most countries that embrace such ideologies. The ideology of rehabilitation based on punishment still remains as dominant global paradigm [15]. Until today, laws pertaining drug as well as strict rehabilitation policies with campaign against drugs and total abstinence is being strongly hold by many countries including major countries like United States of America and Britain. Thus, the prohibitionist certainly against the principles, policies and practices of harm reduction particularly through the Needle and Syringe Exchange Programme (NSEP).

\section{B. NSEP IMPLEMENTATION AND LAW ENFORCEMENT DILEMMA}

Analyses of the literature review found that problems with implementing the NSEP arised due to the conflict of law and much being discussed by previous researchers from the police jurisdiction point of view. Chatterjee [16], Davis, Burris, Kraut-Becher, Lynch, and Metzger [17], Beletsky, Macalino, and Burris [18], Midford, Acres, Lenton, Loxley, and Boots [19] and Lough [20] were among researchers that focused on the challenges of police acceptance towards the implementation of NSEP. Chatterjee [16] and Davis et al. [17] tends to focus on how police operations in combating drugs indirectly contributes to a significant impact on declining participation in the NSEP. Whereas Beletsky et al. [18] not only discussed the police operation and its effects towards NSEP but also emphasised that police behaviour and attitudes towards IDUs as significantly created their negative interactions. Midford et al. [19] and Lough [20] nevertheless have earlier discussed the same findings as Beletsky et al.

[18].

The challenge of police involvement in the NSEP in Malaysia are contradicting with NSEP philosophy, which do not focus on zero tolerance with the National Drug Policy [21 - 22]. The contradiction further affected police commitment to enforce the Dangerous Drugs (Special Preventive Measures) Act 1985. During police operation at the NSEP outreach area, the addicts were frightened and reluctant to come forward to exchange needles with NSEP workers [16-18]. Up to now, although the NSEP has been carried out its operation for the past few decades, the IDUs that use the NSEP services still have bad experience dealing with police [23]. Police operations being considered as decreasing the outreach areas although they are responsible in enforcing the laws relating to drug abuse.

Criminal convictions turns syringe sharing as preferred option by the IDUs compared to being caught with injection equipment and have to face punishment. Many IDUs were afraid of being caught with injections equipment without medical prescriptions. IDUs do not want to be seen buying needles and syringes from pharmacies or clinics [24]. A study of the NSEP implications among IDUs in China discovered that majority of the respondents they met either threw or hid the used syringes. This was intended to avoid being sent to rehabilitation centre if being caught by the police [34-36]. Indirectly, clashes with the police are certainly things that addicts try to avoid and this could affect their participation in the NSEP when they need to go out for needle exchange. Sharing the injection equipment as an implication will continue to be dominant as i) it is a common practice in drug use and ii) each time getting a new syringe or injection equipment is a difficult task. Thus, the multisectoral support of the Dangerous Drugs (Special Preventive Measures) Act enforcement agencies such as the police is essential in maximising the effectiveness of the NSEP and reducing the domination of needle sharing risk. However, inter-agency collaboration is not an easy task.

\section{POLICE DISCRETION IN NSEP}

The enforcement agency requested the police for their cooperation and discretion not to operate in the NSEP outreach area, not to detain their clients and not sending them to the rehabilitation centre. This is because the NSEP enforcement believe in the philosophy that efforts to stop dependence on drug as experienced by the addicts at rehabilitation centres are less practical [23, 37]. Drug addicts should be taught to reduce their addiction by adopting safe addiction. Therefore, police arrests and convictions for two-year rehabilitation punishment at the institution are also considered irrelevant. Thus, police cooperation in giving discretion not to arrest NSEP clients is greatly needed by NSEP programmers. Moreover, police discretion has been one of the indicators in improving the achievement of NSEP objectives. 
The concept of discretion is the most recently recognised aspect of police commissioning. However, its scope and limitations are still unclear and often being misunderstood not only by the police but also by the public. The role of the police in enforcing the law is largely dependent on the discretionary element as there is space allowing for option or more practical decisions made that suits the situation, which not necessarily without the limitations of the law alone [25].

Discretion plays a role in every facet of criminal law. The criminal justice system in the United States of America for an example, allows for the widely use of discretion through the police responsibilities, lawyers, judges, prosecutors, prison officers and parole officers [26].

However, the discretion rendered begins with the initial agency or gate keeper in the criminal justice system, i.e the police. The police is the one that need to make decision to take any legal action and whether they need to officially give discretion or otherwise in any enforcement process [27]. It is a difficult choice for police personnel because discretion is a form of formal action by police using self assessment based on experience in interpreting the harm of a particular criminal behaviour [28,26,29]. According to Gaines \& Kappeler [30] and O'Connor [31], three factors that justify the use of police discretion are i) the situation or the burden of misconduct, ii) the police organisation factor (the organisation internal with regards to what is being allowed in administrative manner for the police) and iii) environmental factors (local community and current political culture according to locality) by taking into account public interest as a priority. Environmental factors are becoming more complex because it concerned detrimental effects of discretion towards the public. When the public flaunt individual offenses as serious and of great harm, it is likely that the police will be less in giving discretion in any misconduct involving the crime [25]. In this situation, it is understood that police discretion are influenced by environmental factors.

In general, there is no discretion that is exempt from the supervision of the law. Futhermore, many policemen understand that no discretion could be given in excessive misconduct or in violation of the law. Each discretion requires sturdy justification and is still bound by laws, regulations, the norms of the society and standard guidelines in police tasks.

Nonetheless, questions arised on how far the police could grant discretion to the implementation of the NSEP? What about the police officer point of view on the need to practice discretion towards NSEP clients? The questions were the justification on the need for a study to be conducted to identify police acceptance towards NSEP.

This article will further discuss reasons why exercising discretion to the NSEP clients is a challenge for RMP as a law enforcement agency.

\section{RESEARCH OBJECTIVE}

The two main objectives aimed in this study are i) to identify types of discretion given by the RMP to NSEP clients and ii) to explore the challenges that contribute dilemma to the RMP in practicing indefinite discretion to NSEP clients.

\section{RESEARCH METHODOLOGY}

This study uses a qualitative research approach, in the form of an exploratory case study. Methodologically, the study has selected agency as the unit of analysis. A total of five (5) RMP officers named by the Narcotics Crime Investigation Department (NCID) were selected as informants representing the agency. An important criterion set for informants is the officers must be the RMP representatives in the NATF (National AIDS Task Force) unit for the NSEP.

Data collection is being carried out at the agency by using in-depth interview methods. Each informant was interviewed on an average of two to three series. The scope of the interview was based on analysis of previous research on Harm Reduction, NSEP, agency network and the duty of police as law enforcement $[25,1,2,32]$.

The study applies the data analysis method used by Blaikee [38], Fortune, Reid \& Miller [39] and Braun \& Clarke [40] for guiding data analysis processes. The inductive analysis method require researchers to initially find and identify several sub-themes and will then form a major theme, followed by forming main themes. A comparison was made to analyse the similarities and differences between the themes. Similar data segments were then being classified under the same cluster. The differences for each data segment were also being examined and assembled. The analysis of the themes derived from the interview data in this study is being conducted inductively.

\section{RESEARCH FINDINGS}

This section will discuss types of discretion and the challenges encountered by RMP in exercising discretion to NSEP clients.

\section{Types of discretionary conferred by the RMP to the NSEP clients}

The duty of policeman is basically in a discretionary manner as it involves the act of either setting evaluation or providing choices. Each police tasks especially at the micro level involves a particular officer making the choice whether to open investigations, questioning, investigate, detain, giving warn, consulting on any appeal, choosing a charge, close a case or prosecute in court [25]. Discretion may take place when arresting clients, take legal action, court hearings and even upon sentencing. Discretion being used by authorised police officer that provided them freedom to decide on how to act or otherwise against any law enforcement. However, the police are still governed by policies or guidelines in their discretion. As a matter of fact, the discretion cannot be given arbitrarily.

Definitely there is no standard procedure of the discretion (for NSEP). It has no Standard Operating Procedure (SOP). Therefore, the discretion being practised by the police would be according to the individual (the particular policeman), his/her experience, his/her knowledge that will be used when he/she preventing something based on his/her discretion.

The results of the analysis
found that police were
requested to practice
Published By:
Blue Eyes Intelligence Engineering
\& Sciences Publication


discretion towards the NSEP clients as follows:

i) Provide an opportunity for clients to come forward to make needle exchange in the NSEP outreach area.

ii) Take no legal action or detain NSEP clients who are proven involved in the programme if they were met outside the NSEP outreach area during the drug operation.

Discretion to allow client to go to NSEP outreach area to exchange needle

Police and the agency implementing NSEP have agreed that there will be no police operation (ADDICTS OPS) to besiege and detain addicts within a 50 meter radius of the needle exchange programme area. The consideration would be given by providing NSEP an opportunity to increase numbers of IDU to come out and obtain clean needles.

For NSEP, this is our discretion, we were asked to give opportunity for the programme to be carried out in the location parameters within a distance area in which we were required not to take action as the client is seeking services. We were asked for discretion because the programme did not provide drugs to its clients. We will not interrupt within a radius of 50 meters. We will take action if it is outside the radius.

Police were aware that IDUs are likely to be terrified to join the NSEP if they feel insecure about the possibility of being arrested.

Discretion for not taking action or detain NSEP outside outreach area

The informant that being interviewed stated that the police were requested to give discretion not only to conduct ADDICTS OPS in the NSEP area but also to not taking action against clients that was within 50 meters radius in the NSEP outreach area. Besides, the police were also expected to extend discretion without arresting clients even outside the NSEP locality.

The addict may be automatically considered to be an NSEP client but we expect them to present their ID cards in the event of police operation... we were asked not to take action against client within 50 meters. We were also asked not to take action on NSEP clients that having small amount of drugs with them.

Both forms of discretion stated by the respondents were also being inserted in the RPM Standard Operation Prosedure of the Narcotic Crimes Investigation Department. It was moulded in collaboration between RMP with the agency who implement the NSEP and the Ministry of Health. The findings demonstrates that the police have practiced discretion towards NSEP clients but are still subject to the priority of abiding the law.

However, further analysis from the data of the studies found the existence of challenges for the police to permanently exercising the use of discretionary for the NSEP.

\section{The RMP challenges in exercising discretion towards NSEP clients}

The analysis found that it is difficult for RMP to give discretion to NSEP clients because:

i) the discretion not to arrest NSEP clients whose having drugs or injections equipments are against the law

ii) the NSEP clients may abuse the discretion since their important identification information were not being provided by the programme organiser.

iii) the police should pay close attention towards public interests as permanent discretion may affect public perceptions on the intergrity of police and its duty.

i) Discretion that is against the law

The discretion practiced by the police is subjective. Informant that being interviewed indicated that the RMP could withdraw the discretionary used towards the NSEP. Police personnel is being controlled by guideline of their services in terms of giving discretion. These guidelines may change from time to time in line with changes in the protection of the public interest (Bronnit \& Stenning, 2011). According to the respondents, although the police agreed to allow discretion by not conducting operation (ADDICTS OPS) at the time of needle exchange, but to give discretion to the addict in possession of drugs and injection equipment are still considered as offenses. It is the principal of the police that they could not give discretion on any evidence of drug possession.

...we can accept the discretion so that we do not interrupt the perimeter area where the NSEP being carried out, it is ok...but when it comes to drug possession, we actually unable to have any discretion on it. The NSEP organiser did requested, why not we consider discretion for this client. This client have needles so they must have intention to possess drugs. Meaning that when they receive this free needle, it is impossible the addicts (client) want to put water in the syringe. He must have buy drugs. Haa this is the problem.

Certainly the clean needle that was originally 'halal' (legal) to own and use could be considered as wrong if the owner portray the 'haram' (illegal) activities of drug abuse. The needle is 'halal' but the drug is 'haram'. This understanding could be concluded by analysing how the following respondents assessed the challenge of giving discretion to the programme ...

When there's a drug with him/her, it's an offense. The question of discretion supposedly should not arise. Meaning that giving discretion by allowing them to have even a small amount of drugs and not arresting them is actually against the law. We are giving unlawful discretion. The truth is that is not a discretion. Even though he/she is within a 50 meter radius but committing crime, still need to take action against him . 
Although the NSEP targeting intervention to reduce HIV infection among IDUs, it appears that the police still give priority to protecting the public interest in compliance with the law. The contradiction between the needs of NSEP organiser and the the police priority to follow the law has been a challenge to the police in giving discretion towards the programme.

\section{ii) Abuse of discretion by NSEP client}

The concept of discretion is slightly confusing especially to agencies or individuals who do not understand it. For the purpose of this article, the concept of discretion tends to be vague, especially about the discretion not to detain NSEP clients during drug operations. In addition, RMP's tendency to be discretionary is also found to be strongly associated with the transparency of NSEP facilitator in providing detailed information about their clients.

Studies discovered that failure to do so has led to technical problems caused by the intransparency of specific identity card (ID) for NSEP client. The NSEP client ID (ID) card do not have important identification detail about who they are. The police would consider that the abusement of discretion could happen in this situation when anyone could claim to be an NSEP client and ask for discretion not to be arrested.

Interview data analysis revealed that police were willing to use their discretion only if the detained IDUs could provide prove that they were NSEP clients. The discretion would be given by releasing IDUs to the NGOs of the programme once they have been certified as NSEP clients. However, it appears to be always a problems when there are queries in NSEP client ID card and causing difficulities to the police for verification purposes. The client ID card contains only the identification code number without any other details such as name or photograph of the card owner. The police officers that being interviewed revealed that despite the NSEP (Drop In Centre-DIC) emergency telephone number was also being displayed on the card, they still find it difficult to obtain confirmation about client as the DIC employees themselves could not be reached. In fact, in most cases, the DIC unable to verify the detained IDU as their client.

When the person doesn't show he/her ID card, even if he/she claimed from NSEP, we cannot accept it. We need to take legal action, arrest, make urine test. We will send to hospital if it is positive, examine, and we will send to the rehabilitation centre when it is confirm that he/she is a drug addict.

In the issue encountered by the NGOs (NSEP organiser) as well as the police pertaining the ID card, the police considered it as not transparent meanwhile the NGOs retain the confidentiality of their clients. We do not fully agree with the system in keeping confidential of IDU identity applied by the NSEP. It's a bit of a hassle for the police, especially in terms of ID verification. Is it true that the one that carry the ID card is the real card holder? ID must be transparent. No need to keep it a secret. It save more time for inspection... we want to avoid the IDU from abusing the programme.

Besides, even though the IDU possess an ID card, the police still has to adhere to the standard operating procedure (Standard Operating Procedure) on arresting where they have to bring detained IDUs during operations to the police station for urine tests. NSEP clients are likely to be released on a discretionary basis but when there is no verification of information by the DIC, and IDU is referred to solely by ID card number, the IDU is also subject to a detention procedure such as other IDUs that are not an NSEP clients. Doubtful of the ID and verification information failure by the NSEP organiser have made it difficult for the police to give discretion.

iii) Discretion affects public opinion on police integrity

NSEP in Malaysia also has a Drop-In Centre premises in residential areas that being freely visited by clients. Certainly the presence of clients at the premises or in the outreach area near the residential area could be noticed by the surrounding residents. The analysis findings also discovered that police received complaints from the public about frequent client presence near residential areas or government health clinics. The informants of this study stated that it is a priority for the police to respond to public complaints on all matters related to drug crime including programmes involving addicts such as the NSEP.

The nearby residents at the outreach area lodge complaint. (Complaint) is easy, when they lodge complaint they'll just mention drug addict ... they wouldn't know the individuals are methadone or NSEP clients. To whom they make the complaint to? Definitely to the police. So, should the police act on it or not? Absolutely we must take action because it is the police jurisdiction. When action being taken by the police, arrest or expel clients and etc., NGOs and NSEP organiser would claim that police are not giving cooperation and do not give discretion.

This situation caught RMP in dilemma between fulfilling its discretion for the NSEP or carrying out their duties in the interest of public safety and complaints.

In addition to adhering to the police services policy to respond to every public complaint, all respondents interviewed also highlighted the importance of police in maintaining their integrity in the community. Informants were concerned about the image of the police when giving favor to the programme even if indirectly. It is expected that the public would not accept the fact if the police giving discretion to the NSEP by not patrolling regularly at the needle exchange area although complaints had been made. The basics of this concern could be identified through the following interviews with respondents:

...sometimes if the public had made noise (complaint) then only (police) takes action. The police would have to take action otherwise they would accuse police is not doing their work. Police can give order not to interrupt the programme, the only problem is the public perception. All this while, society has considered addicts as scum of society. Therefore, the concept (running the programme and giving discretion) causes the NSEP unacceptable. People were making noise when their places filled with drug addicts. The police would then could not say that they do not want to disturb the NSEP outreach area.

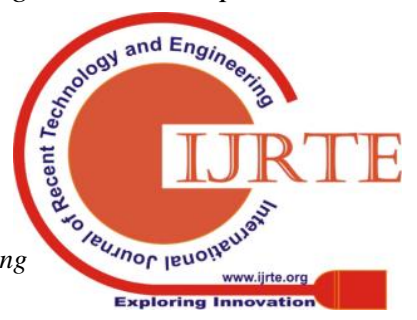


Even though it has been admitted that discretion being practice by police in their duty but Bronnit \& Stenning, [25] thinks that discretion would be able to tarnished public confidence towards them. The image of the police as the authority in ensuring public safety will certainly queried by the society. Especially when the public do not understand the purpose of the discretion itself (for the purpose of this article it refers to the discretion towards the NSEP and the drug addict involved). This findings is in line with a study conducted by Lough [20], Midford et al. [19] and Beletsky et al [18] who discovered that police pays attention to public expectations on police image and their responsibilities in NSEP.

\section{DISCUSSION AND CONCLUSION}

Harm reduction interventions through NSEP were designed to increase IDU access to sterilised injection equipment and safe addicting activities. The approach transforms existing perceptions of drug problems from the perspective of a criminal justice to a public health perspective. However, as a country that supports zero tolerance for drugs, the implementation of the NSEP under the harm reduction strategy is still controversial in Malaysia. This study has successfully highlighted the challenges of implementing the NSEP that is designed based on compliance with the law. The implementation of the NSEP has been challenged by the difficulty of providing permanent discretion particularly to the clients and programmes in general. The finding supports previous studies conducted by Chatterjee [16], Davis, et al. [17], Beletsky, et al. [18], Midford, et al. [19] and Lough [20]. The study by Beletsky et al. [33] pointed out the importance of ensuring police discretion practices are in line with the law especially in assessing how far the police could authorise IDUs in possessing clean needles for drug abuse purposes.

However, police were likely to be less committed to the programme as their duties are entirely subject to the police act and ethics. The Dangerous Drugs (Special Preventive Measures) Act has designed the agency to evaluate the drug abuse problems as issues of law and security. So anything involving drug addicts would also drag the control of law and public safety issues along with it. The results of this study demonstrates the poor coordination of roles between NSEP agency and the police as the enforcement especially in giving discretion to NSEP clients.

The discretion of the police is crucial for the NSEP to encourage IDUs to come out for needle exchange without fear of being caught by the police. Police discretion is needed by not detaining clients despite operations nearby NSEP areas. NSEP enforcement agency, especially the state Health Department and the Malaysian AIDS Council is looking forward the cooperation of the police for not interrupting the needle exchange session that being carried out. The organiser certainly do not want police operations to cause clients discomfort and fear that would make them refuse to participate. The refusal definitely will affect the involvement of client into the programme and it will be difficult for the implementer to approach the IDU. However, this discretion could not be easily achieved by the NSEP or the police.

There are three main factors making it difficult for the police to exercising discretion: i) The discretion given is against the law ii) it is difficult to verify NSEP client identity card (ID card) because it do not contain important identifying information, which could eventually being misused to obtain immunity from being detained. In addition, iii) the police still have to respond to public complaints about NSEP clients making any discretion not to interrupt IDU areas sometimes has to be withdrawn. The police also take it seriously if their integrity being questioned by the public as it is affecting the security of the country by giving discretion in relation to law enforcement.

The discussion of the findings of the study is further enhanced by emphasising the role of social factors in this discretionary practice. The analysis of this research data shows that earlier discussion on the clashes do exist between the NSEP organiser, the police and the public. In more detail, giving discretion becomes difficult caused by conflict of interest and focus. The differences of interest identified are 1) the agency's expectations of police discretion being seen as providing opportunities and prioritising clients safe addict activitie 2) the police's willingness to conduct drug operations on a regular basis is in accordance with law enforcement procedures and 3 ) The tendency of the public to question the integrity of the police in giving discretion to NSEP clients is that they accept that drug addiction is a social problem and a crime to the public safety. The collision of these three expectations illustrates that it is not easy to solely believe on the concept of discretion in procedure of the law especially when no changes being been made to the act.

However, this effort requires long period of time as the integration definitely require prior changes to the existing social policies and laws pertaining to drug.

As such, it is recommended that the NSEP take into account the higher commitment of the police on giving discretion. Deeper collaboration between the various agencies involved in the NSEP should include the following efforts:

a) formulate a

framework to integrating existing drug policies by 
ensuring that the laws on drug would pay more attention to harm reduction

b) to ensure that there are effective methods in assessing the outcome of the harm reduction intervention. This includes developing data collection system on how well the NSEP could reduce the risks of HIV/AIDS

c) promoting and enhancing inter-sectoral cooperation as a way of collaboration (integration) in achieving the objectives of reducing demand (supply of drugs) and reducing harm (resulting from drugs)

d) formulate a common understanding between the relevant agencies on how harm reduction modules should be implemented

e) develop an integrated training strategy (integration) for the police and other relevant agencies.

Additionally, the National AIDS Task Force for the NSEP in Malaysia was found not initiating legal practitioners commitment (lawyer and legal advisor). Thus, it is suggested that a study focusing on the legal practitioners principle from all agencies to be conducted. The purpose of this study from the perspective of law is to validate the syringe exchange programme in Malaysia. It is important as a prior attempt to integrate the role of agencies that have always been bound by laws, for instance, the police that enforcing the Dangerous Drugs (Special Preventive Measures) Act 1985. Moreover, the study is expected to serve as a preliminary effort to understand the effective method approaches to integrate harm reduction in the act of drugs in Malaysia. When the legal stance could be identified, further efforts on how to apply harm reduction into the Zero Tolerance module that has become drug policy in Malaysia could be developed.

In conclusion, the implementation of the NSEP observes value conflicts when a 'halal' (legal) clean needle became 'haram' (illegal) when the purpose of possessing the needle is for drug abuse. The colliation of these values needs to be realised and not being taken lightly by NSEP organiser. Although the purposed of changes to the public health policy and drug rehabilitation developed by the NSEP were to increase IDU access to safe addicts, the implementation would become difficult without the cooperation of the police as the law enforcement. Collaboration between police, public health agencies as well as drug treatment and rehabilitation agencies have great potential to developed new methods and interventions to reduce HIV/AIDS risk behaviors caused by drug abuse. Each agency would be able to create a multisectoral working network by identifying points of common goals between agencies. However, initial efforts to integrate NSEP ideas into the existing laws on drug would first need to be addressed. It is important so that the impact of drug abuse issues be well aware of from time to time and will not continue to be a threat to national security.

\section{ACKNOWLEDGEMENT}

This research has been sponsored by the Universiti Kebangsaan Malaysia (UKM) under the Young Researcher Grant. It is also not possible for this study to be completed successfully without the commitment of the UKM and the Royal Malaysian Police Narcotic and Crimes Investigation Department.

\section{REFERENCES}

[1] D. Mogg, and M. Levy, "Moving beyond non-engagement on regulated needle-syringe exchange programs in Australian prisons," Harm Reduction Journal, 6, 7, 2009.

[2] M. M. Philbin, R.Lozada, M.L. Zuniga, A. Mantsios, P.Case, C. Magis-Rodriguez, C.A. Latkin, and S.A Strathdee, "A Qualitative assessment of stakeholder perceptions and socio-cultural influences on the acceptability of harm reduction programs in Tijuana, Mexico," Harm Reduction Journal, 5, 36, 2008.

[3] UNAIDS, “GLOBAL REPORT : UNAIDS report on the global AIDS epidemic 2013," Joint United Nations Programme on HIV/AIDS (UNAIDS), 2013.

[4] I. Baba, "HIV/AIDS: Cabaran dan kesan kepada masyarakat Malaysia," Dalam Omar, Roziah \& Pandain, Sivamurugan (ed). Malaysia: Isu-Isu Sosial Semasa. Kuala Lumpur: Unit Penerbitan ISM, 2005.

[5] Memoona Hasnain. "Cultural approach to HIV/AIDS harm reduction in muslim countries," Harm Reduction Journal, 2(23), 2005 doi:10.1186/1477-7517-2-23.

[6] S. J. Rogers, and T.Ruefli, "Does harm reduction programming make a difference in the lives of highly marginalized, at-risk drug users?" Harm Reduction Journal, 7(1), 2004.

doi:10.1186/1477-7517-1-7

[7] C. J. Strike, T. Myers, and M. Millson, "Finding a place for needle exchange programs," Critical Public Health, 14(3), 261-275. 2004

[8] T.Tammi, and T. Hurme, "How the harm reduction movement contrasts itself againts punitive prohibition," International Journal of Drug Policy, 18, 84 - 87, 2007.

[9] G. Reid, K. Adeeba, and S. Kaur Sran, Rapid Situation Assessment of Malaysia 2004. University of Malaya Kuala Lumpur : Infectious Disease Unit Publishers. 2005.

[10]N. Stafford, "Using Words : The harm reduction conception of drug use and drug users," International Journal of Drug Policy, 18, 88 - 91, 2007.

[11] G. Reid, K. Adeeba, and S. Kaur Sran, "Malaysia and harm reduction: The challenges

and 
responses;" International Journal of Drug Policy, 18, $136-140,2007$.

[12] P. O'Hare, R. Newcombe, A. Matthews, E. Bunning, and E. Drucker, The reduction of drug related harm. London : Routledge. 1992.

[13]E. Drucker, and A. Clear, "Harm reduction in the home of war on drugs : Methadone and needle exchange in the USA," Drugs and Alcohol Review, 18, (1) 103 - 112, 1999.

[14] H.G. Levine, "The secret of worldwide drug prohibition. The varieties and uses of drug prohibition," In T. Tammi, $\&$ T. Hurme, (2007). How the harm reduction movement contrasts itself againts punitive prohibition. International Journal of Drug Policy, 18, 84 - 87, 2002.

[15] M.T. Aoyagi, "Beyond punitive prohibition: liberalizing the dialogue on international drug policy," International Law And Politics. Vol. 37 :555 - 610, 2006.

[16]P. Chatterjee, “AIDS in India: Police powers and public health," The Lancet, 367, 9513, 2006.

[17] C.S. Davis, S. Burris, J. Kraut-Becher, K.G. Lynch, and D. Metzger, "Effects of an intensive street-level police intervention on syringe exchange," American Journal of Public Health, 95, (2). 2005.

[18]L. Beletsky, G. Macalino, and S. Burris, "Attitudes of police officers towards syringe access, occupational needle -sticks and drug use : A qualitative study of One City Police Department in the United States," International Journal of Drug Policy, 16, 267, 2009.

[19] R. Midford, J. Acres, S. Lenton, W. Loxley, and K. Boots, "Cops, drugs and the community : Establishing consultative harm reduction structures in two Western Australian locations," International Journal of Drug Policy, 13, 185 - 192, 2002.

[20]G. Lough, "Law enforcement and harm reduction : Mutually exclusive or mutually compatible," International Journal of Drug Policy, 9, 169 - 173, 1997.

[21] Z. Ezarina, I. Baba, A. Azman, N. Sarnon, I. Fauziah, and H. A. Wahab, "Police Involvement in the Needle and Syringe Exchange Programme (NSEP): The Malaysian Experience," Pertanika Journals Social Sciences \& Humanities, 22(S):49-62, 2013.

[22]Z. Ezarina, I. Baba, A. Azman, "Indikator Keberkesanan Pendekatan Pengurangan Kemudaratan dan Cabaran Implementasi di Peringkat Agensi Berkepentingan," The Malaysian Journal of Social Administration, vol 7-8 : 1-30, 2011.

[23] L. Beletsky, J. Cochrane, Sawyer, L. Anne, C. Serio-Chapman, M. Smelyanskaya, J. Han, N. Robinowitz, S. G. Sherman, "Police encounters among Needle Exchange Clients in Baltimore : Drug law enforcement as a structural determinant of health," American Journal of Public Health, Vol. 105 Issue 9 : 1872-1879, 2015.

[24] A. N. Martinez, R. N. Bluthenthal, J. Lorvick and R.Anderson et. al. "The impact of legalizing syringe exchange programs on arrests among injection drug users in California," Journal of Urban Health, 84: 3, 2007.

[25] S. Bronitt, and P. Stenning, "Understanding discretion in modern policing," Crim LJ. 35 : 319 - 334, 2011.

[26] S.Walker, and C. M. Katz, The police in America: An introduction (5th ed). New York, NY: McGraw-Hill Companies, 2005.
[27]R. K. Wortley, "Measuring police attitudes towards discretion," Criminal Justice \& Behavior, Vol. 30, (5), pp. 538-558, 2003.

[28] G. L. Halliday (2009). Police discretion. Western Journal of Criminal Justice.

[29] S.T. Reid, Crime and criminology (11th ed). McGraw-Hill Companies, New York: NY, 2006.

[30] L. K. Gaines, and V. E. Kappeler, Policing in America (4th ed). Cincinnati, $\mathrm{OH}$ : Anderson Publishing, 2003.

[31] T. O’Connor, Police discretion,

Retrieved March 20, 2008, from http://www.apsu.edu/oconnort/4000/4000lect07.html 2004.

[32] Centre for Harm Reduction, The manual for reducing drug-related harm in Asia. Macfarlane Burnet Institute for Medical Research and Public Health. Author, 2003.

[33] L. Beletsky, L.E. Grau, E. White, S. Bowman and R. Heimer, "The roles of law, client race, and program visibility in shaping police interference with the operation of US syringe exchange programs," Addiction, 106(2) : 357-365, 2011.

[34] J. Bargen, "The next step: Developing restorative communities," Criminal Law Journal, (2), pp. 1-5, 2005.

[35] S. Burris, "Drug policing, harm reduction and health : Directions for advocacy," International Journal of Drug Policy, 20, 293 - 295, 2009.

[36] K. Dolan, P. Dillon, and E.Sillins, Needle and syringe programs : Your questions answered. Canberra, Australian Government Department of Health and Aging. 2005.

[37] B. Silverman, C.S. Davis, J. Graff, U. Bhatti, M. Santos, and L. Beletsky, "Harmonizing disease prevention and police practice in the implementation of HIV prevention programs : Up-stream strategies from Wilmington, Delaware," Harm Reduction Journal. 9:17, 2012. doi:10.1186/1477-7517-9-17

[38] N. Blaikie. “Approaches to Social Enquiry: Advancing Knowledge”. 2nd edition. Polity Press, Cambridge. 2007

[39] A. E. Fortune, W. J. Reid, R. L. Miller. "Qualitative Research in Social Work". Columbia University Press, New York. 2014

[40] V. Braun and V. Clarke. "Successful Qualitative Research: A Practical Guide for Beginners". Sage Publication. Thousands Oaks, California. 2013.

\section{AUTHORS PROFILE}

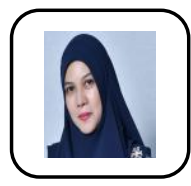


Fauziah Ibrahim (Ph.D)

Lecturer

School of Psychology and Human Development

Faculty of Social Science and Humanities,

National University of Malaysia

43600 Bangi, Selangor,

MALAYSIA.

Email: ifauziah@ukm.edu.my

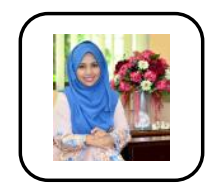

Norul Huda Sarnon (Ph.D)

Lecturer

School of Psychology and Human Development

Faculty of Social Science and Humanities,

National University of Malaysia

43600 Bangi, Selangor,

MALAYSIA.

Email: norul@ukm.edu.my

\section{Nazirah Hassan (Ph.D)}

Lecturer

School of Psychology and Human Development,

Faculty of Social Science and Humanities,

National University of Malaysia,

43600 Bangi, Selangor, MALAYSIA.

Email: nazirah@ukm.edu.my 